\title{
Physical activity, visual impairment, and eye disease
}

\author{
Sharon R. Ong ${ }^{1}$ - Jonathan G. Crowston ${ }^{2}$ Paul D. Loprinzi ${ }^{3} \cdot$ Pradeep Y. Ramulu $^{4}$
}

Received: 8 January 2018 / Revised: 11 February 2018 / Accepted: 21 February 2018 / Published online: 3 April 2018

(c) The Royal College of Ophthalmologists 2018

\begin{abstract}
Numerous studies have demonstrated physical activity is a strong factor in overall health and well-being, and a growing body of literature, reviewed herein, suggests that several eye conditions, including glaucoma, age-related macular degeneration, and diabetic retinopathy, are associated with lower activity levels. Likewise, physical activity levels are lower in persons with worse vision. Research in this area has utilized both self-reported physical activity measures as well as objective measures of activity (i.e., accelerometers), each of which have their own strengths and limitations. Putative mechanisms explaining the association of various eye conditions with physical activity are discussed. It is possible that activity restriction occurs as a downstream consequence of eye disease/visual impairment, that activity restriction causes eye disease/visual impairment, or that causality is bidirectional; evidence supporting each of these theories is put forth. An improved understanding of the relationship between physical activity and eye disease will highlight potential secondary health risks resulting from eye disease, and can help determine whether activity might serve as a readily available preventative measure to prevent specific eye conditions.
\end{abstract}

\section{Introduction}

Visual impairment (VI) and blindness are becoming increasingly prevalent in the United States and around the world as a result of aging populations [1]. A recent study determined that in 2015, among individuals 40 years and older in the United States, 3.22 million people were visually impaired and 1.02 million were legally blind. This represents a $>20 \%$ increase over the last decade, with numbers projected to double by 2050 [2]. Of note, these increases have occurred despite substantial advancement in the treatment of several of the most common blinding conditions.

The current review will focus on the potential bidirectional association between physical activity (PA) and vision

Pradeep Y. Ramulu

pramulu@jhmi.edu

1 University of Maryland School of Medicine, Baltimore, MD 21201-1544, USA

2 Center for Eye Research Australia, University of Melbourne, 32 Gisborne Street East, Melbourne, VIC 3002, Australia

3 University of Mississippi Medical Center, Jackson, MS 392164505, USA

4 Johns Hopkins University, Baltimore, MD 21205, USA loss, particularly as associated with various eye diseases. We examine if PA, a critical component of health, may be impeded by vision loss, and whether PA could possibly protect against vision loss. If PA can be shown to be an effective method to prevent vision loss, then it would offer a low-cost, non-invasive treatment option with other positive benefits. Alternatively, if reduction in PA is a downstream consequence of VI, then it underscores the need for future research aimed at identifying specific evidence-based strategies to promote PA within this sedentary population.

\section{PA and health}

Numerous studies have demonstrated that PA is a strong determinant of overall health and well-being. For instance, PA can beneficially alter several cardiovascular risk factors $[3,4]$, as well as lower one's future risk of type 2 diabetes $[5,6]$. PA also has proven benefits to the nervous system, suggesting it may exert similar positive effects on the visual system given that many parts of the eye share embryologic origins with that of the rest of the central nervous system. Improvements in brain function, cognition [7, 8], and even brain structural volumes have been noticed with aerobic activity interventions [9]. PA also protects against the development of neurodegenerative diseases, including Alzheimer's disease [10], and has been shown to improve 
cognitive function in Alzheimer's patients [11]. There is also evidence of a relationship between PA and positive effects on mood and anxiety, including decreases in the risk of incident depression [12] and improved symptoms in persons with pre-existing depression or anxiety [13-17]. Given that VI has been shown to be associated with increased anxiety [18], PA may offer benefits with regard to not only the underlying ocular disease processes but also to the downstream psychological effects of disease.

The broad array of systems affected by PA suggests substantial secondary consequences of vision loss if habitual PA is reduced in individuals with VI. These consequences go beyond the vascular and neurological conditions listed above. For example, PA can decrease the risk of osteoporotic fractures in older individuals and have long-lasting effects on bone health [19]. It also affects body composition, increasing lean body mass through increasing skeletal muscle mass and reducing fat mass [20-22]. PA has even been associated with lower rates of various malignancies, including colon [23] and breast cancer [24], suggesting that poor PA resulting from VI may produce significant secondary comorbidity.

\section{Measuring PA}

Assessing the relationship between PA and visual problems requires that $\mathrm{PA}$ be quantified accurately - a challenge given that PA is a complex, multi-dimensional behavior that can be further categorized in terms of frequency, mode, duration, and intensity. This has practical significance for evaluating the value of both previous and future studies focusing on the relationship between PA and eye disease. Categorization of PA has largely been accomplished through two methods-subjective assessments (questionnaires); and objective methods (wearable devices).

Common self-reported measures to capture PA include diaries, PA logs, and recall surveys and questionnaires. For example, the National Health and Nutrition Evaluation Survey (NHANES) assessed mode, frequency, and duration of recreation over a 30-day period. Other tools such as the Compendium of Physical Activity were developed to capture intensity of activity by coding data from PA records, logs, and surveys [25]. Intensity of a specific activity can be expressed in metabolic equivalents - the ratio of working metabolic rate to a standard resting metabolic rate-allowing for estimation of energy expenditure [25, 26].

Objective measurements of PA have emerged as the gold standard for quantifying PA, most commonly through measurements of steps and minutes of greater (non-sedentary) activity using accelerometers. Studies suggest they accelerometers are a more reliable method of capturing true PA as compared to self-reported measures. Accelerometers typically record activity in epochs of programmable length, in which activity is quantified as steps and further categorized by intensity of motion over each study epoch based on the amount of detected movement adjusted for body size [27]. More recent methods involve analysis of triaxial accelerometry data obtained at sub-second resolutions using complex statistical methods to more accurately predict the amount of energy being expended [28]. Participants typically wear accelerometers during waking hours, and data from the accelerometers are summarized as the mean steps, counts (a raw metric of detected acceleration), or daily minutes spent in light, moderate, or vigorous PA [29].

Several studies have compared subjective measures of PA to objective measures, and have suggested potential limitations with the subjective assessment of PA [30-32]. Questionnaire accuracy may vary with the amount of time spent at greater levels of activity [33]. Self-reported PA is also poorly correlated with accelerometer-defined PA [34] and has weaker associations with biomarkers-body mass index, waist circumference, glycohemoglobin, insulin, and homocysteine - than objectively measured PA, suggesting that it is less reflective of actual activity and health [35].

While accelerometer-defined activity is the preferred method of measuring PA, it still exhibits some issues with accuracy depending on inconsistencies in device type, placement [29], age, and health of the wearer. Most studies assessing the validity of accelerometer measurements have included young, healthy volunteers, which were shown to be problematic when translating results to older or obese populations due to differences in speed of movement, gait mechanism, and body composition [36, 37]. Data suggest that accelerometers can underestimate steps in persons with short shuffling gaits [38-40], indicating that data may not be accurate in the visually impaired for which specific differences in gait patterns between those with and without VI have been noted [41]. Studies have shown PA patterns measured by accelerometers differ by age, in which further validation is needed in older populations, and the type of walking task [42]. Individuals with functional limitations, including those with physical disability, also introduce complications when comparing the accelerometer-defined PA and energy expenditure. For instance, the accelerometer algorithm extrapolating accelerometer counts per day for a stroke patient likely yields inaccurate estimates of PArelated energy expenditure for that individual [43].

Objective PA monitoring through wearable devices is rapidly evolving, and new devices including new features (i.e., heart rate and sleep monitoring) are becoming increasingly available. While commercial-level devices for measuring activity are comparatively less expensive and give general data about steps and PA intensity, research-grade devices more accurately quantify intensity and can sample at higher frequencies. In a recent study assessing the validity of 
consumer-level activity monitors in healthy adults, these monitors demonstrated highly accurate measurements of steps and sleep duration, but were much less accurate for measurements of total daily energy expenditure and moderate to vigorous PA (MVPA) [44]. Moreover, the validity of each type of consumer-level device varied markedly. Additionally, while the feedback provided by consumerlevel devices contributes to their great potential as intervention tools, it may lead to changes in participant behavior, making such devices undesirable for measuring habitual PA.

There is a lack of clarity regarding which measures of PA are most relevant to health, making it uncertain whether the additional information captured by medical-grade accelerometers is valuable. A study examining the health benefits of high- versus low-intensity exercise programs yielded unclear conclusions as to which confers greater health benefits [45]. Current literature also provides conflicting evidence as to whether there are equal benefits of continuous versus fragmented activity, a distinction that is better evaluated through medical-grade accelerometers [46-48]. Light-intensity PA has also been shown to have beneficial effects on serum brain-derived neurotrophic factor (BDNF) levels and levels of other growth factors, suggesting that light activity, which are significantly more common in older individuals than moderate/vigorous activity, may be sufficient to accrue the positive benefits of movement [49]. More studies are required to better understand the specific patterns of activity restriction that result from VI, and the types of activity, which are of greatest benefit with regards to protecting against eye disease.

\section{PA and VI}

Several studies have examined the association between PA and VI without devoting significant attention to the disease (s) producing VI. A study examining self-reported participation in leisure activities among elderly patients with low vision demonstrated significant declines in five of the six activity categories over time. Significant changes were seen in participation in active crafts and participatory sports [50]. In NHANES, a large population-based study of US adults, persons with bilateral visual field (VF) loss demonstrated $30 \%$ less time spent in MVPA as compared to those without VF loss [51]. Separate NHANES work demonstrated that VI (corrected VA worse than 20/40) was associated with a nearly 50\% reduction in the time spend in MVPA [52]. Of note, no restriction of PA was noted in participants with poor presenting acuity due to uncorrected refractive error (URE). The drastic difference regarding the impact of VI and URE on PA is surprising, and suggests that PA may be a contributing factor to eye diseases that produce VI, as opposed to a downstream consequence [53]. These observations motivate further investigation into the role of PA within specific eye diseases in order to better understand the importance of PA in preventing the development or progression of such diseases.

\section{Intraocular pressure, glaucoma, and PA}

Glaucoma affects $2-4 \%$ of adults over the age of 40 , and will increase in prevalence as the population ages [54]. Many studies suggest that glaucoma affects mobility [55], balance [56], and increases the risk of falling [57] due to VF loss. There have been several studies examining the effect of VF loss seen in glaucoma on PA levels. A recent study assessing the PA of glaucoma patients using accelerometers showed that severity of VF loss was associated with fewer daily steps $(12 \%$ less per each $5 \mathrm{~dB}$ decrement in the bettereye VF) and less time spent in MVPA (21\% less) [34].

Other studies have specifically suggested that more vigorous activity is a means of helping prevent or delay glaucoma. A study examining runners showed that participants with faster $10 \mathrm{~km}$ race performance and longer running distances had lower risk for incident participantreported, physician-diagnosed glaucoma [58].

Mediation studies have yielded insights into the possible direction of causality between VF damage and PA in glaucoma. One study found that severity of VF damage in persons with glaucoma remained associated with $\mathrm{PA}$ even after inclusion of fear of falling in the model, suggesting that activity restriction may not be the result of fear of falling [27]. Of note, this finding was disease-specific, as fear of falling was noted to mediate the association of poor vision and activity restriction in age-related macular degeneration (AMD) patients. These data suggest that VF damage leads to activity restriction through other unknown pathways not involving fear of falling, or that VF damage may actually be a product of activity restriction. Thus, while an effort to replace inactivity with low-risk PA in glaucoma patients may be an important intervention, further studies need to be done to examine what elements are involved in mediating VF loss and PA restriction in glaucoma patients, and to conduct longitudinal studies that can help clarify the direction of causality.

\section{Neuroprotective effects of PA in models of glaucoma}

There is significant evidence demonstrating neuroprotective effects of PA [8], a relationship that has been shown to extend to protection of retinal ganglion cells and their axons against irreversible damage. Intraocular pressure (IOP) elevation is one of many risk factors for glaucoma, though evidence suggests lowering IOP does not prevent 
disease progression in all patients [59]. Thus, therapies combining conventional IOP-lowering approaches with neuroprotective treatments could better preserve vision by protecting neurons, which are reversibly damaged, or likely to be damaged in the future, as part of glaucomatous optic neuropathy [60].

Exercise has previously been shown to be associated with neuroprotection in age-related neurodegenerative conditions such as Alzheimer's disease and vascular dementia [61, 62]. More recent evidence indicates a similar protective effect of exercise in the progression of eye disease. Forced regular exercise in aged mice was shown to protect the aged optic nerve against IOP-induced injury [63]. Furthermore, we observed a case of possible bilateral VF damage reversal in a 30-year-old female glaucoma patient who started a vigorous exercise program. Symmetric bilateral improvements were observed, suggesting partially reversible improvement in visual function as a result of PA. Bilateral improvements were lost when she temporarily stopped exercising, and improved again upon resumption of her exercise program (Fig. 1). Certainly, this individual case is subject to placebo effects as well as artifacts of visual testing, and further research is required to determine if there is a direct protective role of PA on preventing or even partially restoring visual function in glaucoma.

\section{Possible mechanistic explanations of PA and neuroprotection in glaucoma}

Low ocular perfusion pressure (OPP) is a consistent risk factor for higher prevalence, incidence, and progression of

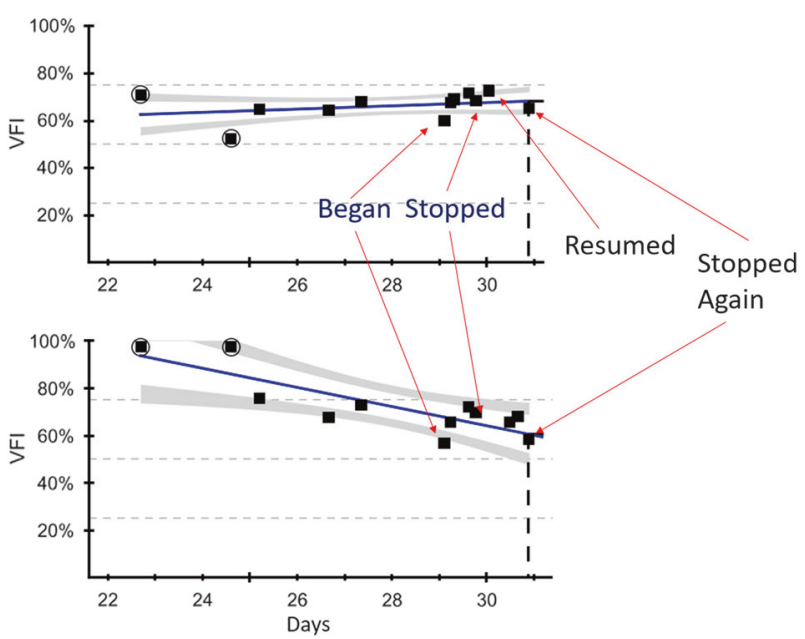

Fig. 1 Case study of visual field improvement with physical activity in a patient with glaucoma. This case demonstrated visual field index (VFI) changes with exercise patterns (defined by a program of running) in a 32-year-old female with actively treated uveitic glaucoma. VFI improved with onset of physical activity, but declined with interruption of exercise open-angle glaucoma (OAG) [64]. Patients who reported active lifestyles in the past have been shown to have lower risk of having a low OPP, suggesting one possible mechanism through which PA might reduce the risk of developing OAG [65].

BDNF is important in maintenance, growth, and survival of neurons, with numerous studies in both rats and humans demonstrating enhancements in cognition mediated by PA-induced increases in BDNF [66]. Both human and mouse studies demonstrate an increase in BDNF release during exercise, while BDNF mRNA expression peaks during the recovery from exercise. $B D N F$ gene upregulation during exercise recovery is thought to promote BDNF accumulation after repeated exercise sessions, eventually leading to a detectable increase in BDNF in specific brain areas [67]. Overexpression of the $B D N F$ gene contributed to retinal ganglion cell protection in an animal model of glaucoma, which was shown to have downregulated $B D N F$ gene expression [68]. Similarly, lower serum BDNF levels, an indication of a sedentary lifestyle, have been observed in glaucoma patients with more advanced VF damage [69], though PA levels were not determined for these patients. Furthermore, studies suggest impaired retrograde transport of BDNF in glaucoma is a possible mechanistic cause of optic nerve atrophy and ganglion cell death [70]. Finally, it has been shown that BDNF is essential for exercisemediated improvements seen in functional recovery of the retina post exercise [71], further supporting the protective role of BDNF and PA in ocular disease.

Lastly, IOP has been shown to be elevated during exercise, possibly due to respiratory and/or body positionrelated and/or muscle exertion-related mechanisms. This elevation in IOP has been postulated to pose a detrimental risk for glaucoma onsent and worsening. Most studies have investigated reductions in IOP after aerobic exercise, but IOP elevations during static strength training exercises [72] indicate that such activities could have a pathogenic role in the development and progression of glaucoma in rare cases [73]. Past studies showing a reduction in IOP immediately or shortly after exercise, as well as a lower baseline IOP in glaucoma patients, suggesting PA might actually have a beneficial effect on IOP [74]. Most studies have focused on the impact of very intense activity on IOP, and there is a need to explore the relationship of light activity on IOP given emerging evidence that even light activity, which reduces sedentary time, can have positive benefits [75].

\section{AMD and PA}

AMD is the leading cause of blindness among people age 50 and older, and there are limited options to prevent progression of this chronic disease, especially in patients 
suffering from geographic atrophy/dry AMD [76]. The pathogenesis of AMD is not fully known, but several mechanisms have been proposed as important in development of the disease, including dysregulation of the complement cascade [77] and oxidative stress [78]. Physical inactivity has been associated with the development of precursors for AMD in the form of macular drusen [79] and may facilitate the progression of vision loss and AMD severity through inflammation and endothelial dysfunction [80].

A nationally representative sample of US adults showed individuals with late AMD spent significantly less time in MVPA than those with early AMD or without AMD over 1week accelerometer trials [52]. In contrast, a recent study in elderly Danish patients with late AMD suggested that patients with late AMD may still be physically active based on self-reported PA, though the type of activities performed may change into less vision-demanding ones as AMD progresses and vision is lost [81]. The lifestyle of different populations and/or the methods used to evaluate PA may account for these observed differences. A report assessing the association between AMD and self-reported PA in the Melbourne Collaborative Cohort Study suggests that past frequent vigorous exercise may be inversely related to the presence of intermediate AMD in women [82], and an investigation of subjectively measured PA and risk of developing AMD over a 15-year period demonstrated engagement in an active lifestyle reduced the risk of developing AMD over 15 years by $70 \%$, as measured through fundus photographs [77]. Another longitudinal study examining self-reported PA in individuals with early or intermediate stages of AMD demonstrated that greater PA levels decreased the risk of progression to advanced AMD [83]. Thus, not only does AMD appear to limit PA but also PA may be protective against the progression of AMD as judged by the few longitudinal studies on the topic. PA may also modify the impact of vision loss on quality of life, as demonstrated by a study of patients with bilateral AMD, where loss of valued activity mediated the relationship between visual acuity and level of distress [84].

\section{Diabetic retinopathy and PA}

With the increasing global prevalence of diabetes, diabetic retinopathy (DR) is set to be the principle cause of vision impairment in many countries [85]. The association between physical inactivity and diabetes is well established [86]. Furthermore, lifestyle intervention and PA have been shown to reduce the incidence of type 2 diabetes mellitus (T2DM) in high-risk individuals with impaired glucose tolerance by $58 \%$ [5], and were more effective than metformin in preventing T2DM [6]. While physical inactivity has been identified as a modifiable risk factor of type 2 diabetes, relatively little is known about the relationship between PA and vision loss seen in DR.

Retina imaging to take measurements of central retinal arteriolar equivalent and central retinal venular equivalent (CRVE) have been used to determine their relevance as a risk factor for vascular disease, including DR [87]. A study assessing the relationship between PA and retinal vascular caliber demonstrated a significant association between low levels of PA and wider CRVE in men, but not in women [88]. Similarly, the Atherosclerosis Risk in Communities study found individuals with self-reported higher levels of PA were significantly more likely to have narrower venular caliber and a lower prevalence of arteriovenous nicking and retinopathy [89]. Together, these studies suggest both low levels of PA and higher levels of sedentary behavior are associated with wider CRVE and could possibly contribute to an increased risk in developing DR.

PA has been associated with improvements in vascular endothelial function [90], and is thus suggested to play a protective role for development of advanced DR through this mechanism. One study examined the association between objectively measured PA and nonproliferative DR, and even modest amounts of PA decreased the likelihood of developing severe nonproliferative DR [91]. Increasing evidence from both animal models and human studies show that chronic inflammatory processes and glucose-induced endothelial dysfunction are related to development, severity, and progression of DR [92]. Thus, the beneficial effects of PA on endothelial function and inflammation may contribute to not only preventing the development of DR but also treatment of patients with DR [93, 94] (Table 1).

\section{Conclusion}

PA has been established as an essential factor of overall health. The relevance of PA to VI may be twofold; the level of PA in an individual may be affected by vision loss, while increased levels of PA may protect against vision loss. In examining relationships between PA and three common eye diseases that lead to VI-glaucoma, AMD, and DR-much evidence supports a possible protective role of PA against vision loss, though longitudinal studies using objective measures of PA and clinical trials designed to increase PA are needed to more firmly establish the truth of these hypotheses. These diseases, particularly at more advanced stages, also largely identify persons as being at higher risk of poor activity. This suggests that an emphasis on maintaining healthy PA levels is especially important in individuals with vision loss. 


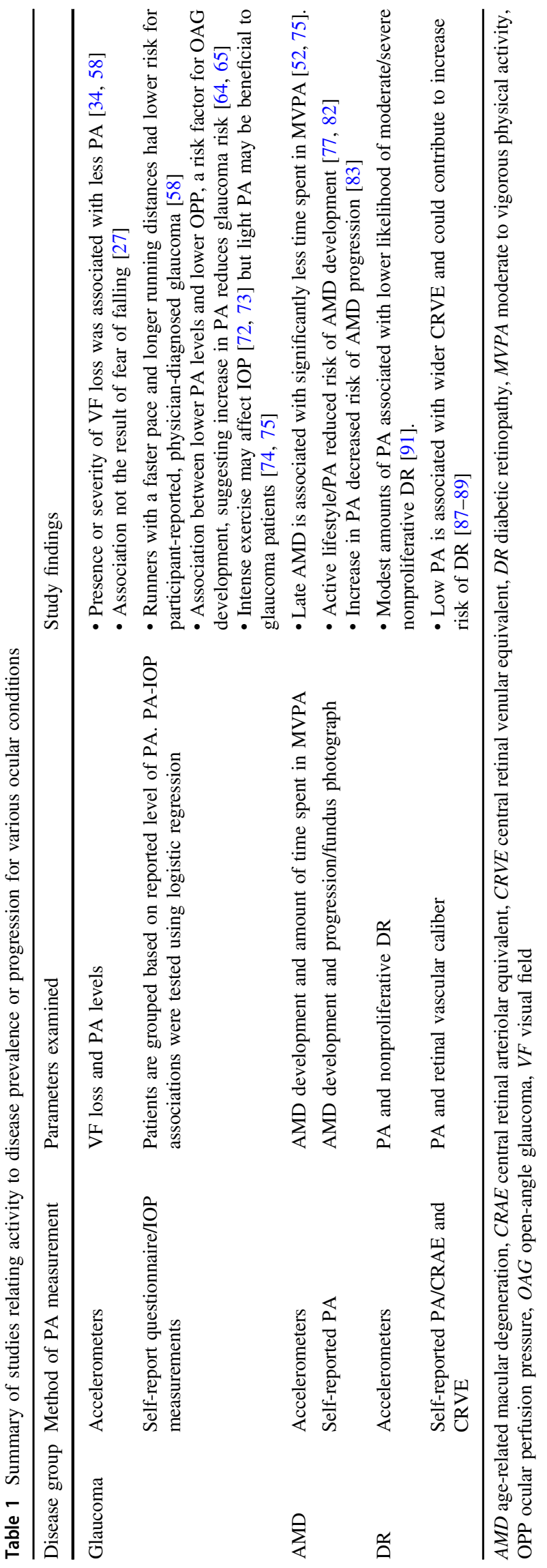

\section{Compliance with ethical standards}

Conflict of interest The authors declare that they have no conflict of interest.

\section{References}

1. Stevens GA, White RA, Flaxman SR, Price H, Jonas JB, Keeffe $\mathrm{J}$, et al. Global prevalence of vision impairment and blindness: magnitude and temporal trends, 1990-2010. Ophthalmology. 2013;120:2377-84.

2. Varma R, Vajaranant TS, Burkemper B, Wu S, Torres M, Hsu $\mathrm{C}$, et al. Visual impairment and blindness in adults in the united states: demographic and geographic variations from 2015 to 2050. JAMA Ophthalmol. 2016;134:802-9.

3. Cornelissen VA, Fagard RH. Effects of endurance training on blood pressure, blood pressure-regulating mechanisms, and cardiovascular risk factors. Hypertension. 2005;46:667-75.

4. Kokkinos PF, Fernhall B. Physical activity and high density lipoprotein cholesterol levels. Sports Med. 1999;28:307-14.

5. Tuomilehto J, Lindström J, Eriksson JG, Valle TT, Hämäläinen $\mathrm{H}$, Ilanne-Parikka P, et al. Prevention of type 2 diabetes mellitus by changes in lifestyle among subjects with impaired glucose tolerance. N Engl J Med. 2001;344:1343-50.

6. Diabetes Prevention Program Research Group. Reduction in the incidence of type 2 diabetes with lifestyle intervention or metformin. New Engl J Med. 2002;346:393-403.

7. Kramer AF, Erickson KI. Capitalizing on cortical plasticity: influence of physical activity on cognition and brain function. Trends Cogn Sci. 2007;11:342-8.

8. Loprinzi PD, Herod SM, Cardinal BJ, Noakes TD. Physical activity and the brain: a review of this dynamic, bi-directional relationship. Brain Res. 2013;1539:95-104.

9. Colcombe SJ, Erickson KI, Scalf PE, Kim JS, Prakash R, McAuley E, et al. Aerobic exercise training increases brain volume in aging humans. J Gerontol A Biol Sci Med Sci. 2006;61:1166-70.

10. Scarmeas N, Levy G, Tang MX, Manly J, Stern Y. Influence of leisure activity on the incidence of Alzheimer's disease. Neurology. 2001;57:2236-42.

11. Maliszewska-Cyna E, Lynch M, Jordan Oore J, Michael Nagy $\mathrm{P}$, Aubert I. The benefits of exercise and metabolic interventions for the prevention and early treatment of Alzheimer's disease. Curr Alzheimer Res. 2017;14:47-60.

12. Camacho TC, Roberts RE, Lazarus NB, Kaplan GA, Cohen RD. Physical activity and depression: evidence from the Alameda County Study. Am J Epidemiol. 1991;134:220-31.

13. Ströhle A. Physical activity, exercise, depression and anxiety disorders. J Neural Transm. 2009;116:777.

14. Blumenthal JA, Emery CF, Madden DJ, George LK, Coleman RE, Riddle MW, et al. Cardiovascular and behavioral effects of aerobic exercise training in healthy older men and women. $\mathrm{J}$ Gerontol. 1989;44:M147-57.

15. DiLorenzo TM, Bargman EP, Stucky-Ropp R, Brassington GS, Frensch PA, LaFontaine T. Long-term effects of aerobic exercise on psychological outcomes. Prev Med. 1999;28:75-85.

16. Roth DL, Holmes DS. Influence of aerobic exercise training and relaxation training on physical and psychologic health following stressful life events. Psychosom Med. 1987;49:355-65.

17. King AC, Taylor CB, Haskell WL. Effects of differing intensities and formats of 12 months of exercise training on psychological outcomes in older adults. Health Psychol. 1993;12:292.

18. Loprinzi PD, Codey K. Influence of visual acuity on anxiety, panic and depression disorders among young and middle 
age adults in the United States. J Affect Disord. 2014;167: 8-11.

19. Cavanagh P, EVANS J, Fiatarone M, Hagberg J, McAuley E, Startzell J. Exercise and physical activity for older adults. Med Sci Sports Exerc. 1998;30:1-29.

20. Broeder CE, Burrhus KA, Svanevik LS, Volpe J, Wilmore JH. Assessing body composition before and after resistance or endurance training. Med Sci Sports Exerc. 1997;29:705-12.

21. McArdle WD, Katch FI, Katch VL. Exercise physiology. Med Sci Sports Exerc. 1991;23:1403.

22. Miles L. Physical activity and health. Nutr Bull. 2007;32:314-63.

23. Lee IM. Physical activity and cancer prevention-data from epidemiologic studies. Med Sci Sports Exerc. 2003;35:1823-7.

24. Lynch BM, Neilson HK, Friedenreich CM. Physical activity and breast cancer prevention. Physical activity and cancer. In: K.S. Courneya and C.M. Friedenreich editors. Berlin, Heidelberg: Springer; 2010. p. 13-42.

25. Ainsworth BE, Haskell WL, Whitt MC, Irwin ML, Swartz AM, Strath SJ, et al. Compendium of physical activities: an update of activity codes and MET intensities. Med Sci Sports Exerc. 2000;32:S498-504.

26. Ainsworth BE, Haskell WL, Leon AS, Jacobs JD, Montoye HJ, Sallis JF, et al. Compendium of physical activities: classification of energy costs of human physical activities. Med Sci Sports Exerc. 1993;25:71-80.

27. Nguyen AM, Arora KS, Swenor BK, Friedman DS, Ramulu PY. Physical activity restriction in age-related eye disease: a crosssectional study exploring fear of falling as a potential mediator. BMC Geriatr. 2015;15:64.

28. Gleiss AC, Wilson RP, Shepard EL. Making overall dynamic body acceleration work: on the theory of acceleration as a proxy for energy expenditure. Methods Ecol Evol. 2011;2:23-33.

29. Catellier DJ, Hannan PJ, Murray DM, Addy CL, Conway TL, Yang S, et al. Imputation of missing data when measuring physical activity by accelerometry. Med Sci Sports Exerc. 2005;37: S555.

30. Shephard RJ. Limits to the measurement of habitual physical activity by questionnaires. Br J Sports Med. 2003;37:197-206.

31. van Poppel MN, Chinapaw MJ, Mokkink LB, Van Mechelen W, Terwee CB. Physical activity questionnaires for adults. Sports Med. 2010;40:565-600.

32. Westerterp KR. Assessment of physical activity: a critical appraisal. Eur J Appl Physiol. 2009;105:823-8.

33. Aadahl M, JØrgensen T. Validation of a new self-report instrument for measuring physical activity. Med Sci Sports Exerc. 2003;35:1196-202.

34. Kasneci E, Black AA, Wood JM. Eye-tracking as a tool to evaluate functional ability in everyday tasks in glaucoma. J Ophthalmol. 2017;2017:6425913.

35. Atienza AA, Moser RP, Perna F, Dodd K, Ballard-Barbash R, et al. Self-reported and objectively measured activity related to biomarkers using NHANES. Med Sci Sports Exerc. 2011;43:815-21.

36. Schrack J, Zipunnikov V, Crainiceanu C. Electronic devices and applications to track physical activity. JAMA. 2015;313:2079-80.

37. Hollewand AM, Spijkerman AG, Bilo HJ, Kleefstra N, Kamsma Y, van Hateren KJ. Validity of an accelerometer-based activity monitor system for measuring physical activity in frail older adults. J Aging Phys Act. 2016;24:555-8.

38. Loprinzi PD, Lee H, Cardinal BJ, Crespo CJ, Andersen RE, Smit E. The relationship of actigraph accelerometer cut-points for estimating physical activity with selected health outcomes: results from NHANES 2003-06. Res Q Exerc Sport. 2012;83: $422-30$

39. Loprinzi PD, Smit E, Cardinal BJ, Crespo C, Brodowicz G, Andersen R. Valid and invalid accelerometry data among children and adolescents: comparison across demographic, behavioral, and biological variables. Am J Health Promot. 2014;28:155-8.

40. Loprinzi PD, Cardinal BJ, Crespo CJ, Brodowicz GR, Andersen RE, Smit E. Differences in demographic, behavioral, and biological variables between those with valid and invalid accelerometry data: implications for generalizability. J Phys Act Health. 2013;10:79-84.

41. Hallemans A, Ortibus E, Meire F, Aerts P. Low vision affects dynamic stability of gait. Gait Posture. 2010;32:547-51.

42. Chen K, Schrack J, Knuth N. Objectively Measured Physical Activity Varies by Task and Accelerometer Location in Younger and Older Adults. Int J Exerc Sci. 2016;9:30.

43. Strath SJ, Pfeiffer KA, Whitt-Glover MC. Accelerometer use with children, older adults, and adults with functional limitations. Med Sci Sports Exerc. 2012;44:S77.

44. Ferguson T, Rowlands AV, Olds T, Maher C. The validity of consumer-level, activity monitors in healthy adults worn in freeliving conditions: a cross-sectional study. Int J Behav Nutr Phys Act. 2015;12:42.

45. Regnaux JP, Trinquart L, Boutron I, Nguyen C, Brosseau L, Ravaud P. High-intensity versus low-intensity physical activity or exercise in patients with hip or knee osteoarthritis. Cochrane Database Syst Rev. 2012;11.

46. Daussin FN, Zoll J, Dufour SP, Ponsot E, Lonsdorfer-Wolf E, Doutreleau $S$, et al. Effect of interval versus continuous training on cardiorespiratory and mitochondrial functions: relationship to aerobic performance improvements in sedentary subjects. Am J Physiol Regul Integr Comp Physiol. 2008;295:R264-72.

47. MacDougall D, Sale D. Continuous vs. interval training: a review for the athlete and the coach. Can J Appl Sport Sci. 1981;6: 93-7.

48. Zuhl M, Kravitz L. Hiit vs. continuous endurance training: battle of the aerobic titans. IDEA Fit J. 2012;9:34-40.

49. Kwon SJ, Park J, Park SY, Song KS, Jung ST, Jung SB, et al. Low-intensity treadmill exercise and/or bright light promote neurogenesis in adult rat brain. Neural Regen Res. 2013;8:922.

50. Heinemann AW, Colorez A, Frank S, Taylor D. Leisure activity participation of elderly individuals with low vision. Gerontologist. 1988;28:181-4.

51. Van Landingham SW, Willis JR, Vitale S, Ramulu PY. Visual field loss and accelerometer-measured physical activity in the United States. Ophthalmology. 2012;119:2486-92.

52. Willis JR, Vitale SE, Agrawal Y, Ramulu PY. Visual impairment, uncorrected refractive error, and objectively measured balance in the United States. JAMA Ophthalmol. 2013;131:1049-56.

53. Zebardast N, Swenor BK, Van Landingham SW, Massof RW, Munoz B, West SK, et al. Comparing the impact of refractive and nonrefractive vision loss on functioning and disability: the salisbury eye evaluation. Ophthalmology. 2015;122:1102-10.

54. Quigley HA, Broman AT. The number of people with glaucoma worldwide in 2010 and 2020. Br J Ophthalmol. 2006;90:262-7.

55. Aspinall PA, Johnson ZK, Azuara-Blanco A, Montarzino A, Brice R, Vickers A. Evaluation of quality of life and priorities of patients with glaucoma. Invest Ophthalmol Vis Sci. 2008;49: 1907-15.

56. Black AA, Wood JM, Lovie-Kitchin JE, Newman BM. Visual impairment and postural sway among older adults with glaucoma. Optom Vis Sci. 2008;85:489-97.

57. Black AA, Wood JM, Lovie-Kitchin JE. Inferior field loss increases rate of falls in older adults with glaucoma. Optom Vis Sci. 2011;88:1275-82.

58. Williams PT. Relationship of incident glaucoma versus physical activity and fitness in male runners. Med Sci Sports Exerc. 2009;41:1566.

59. Heijl A, Leske MC, Bengtsson B, Hyman L, Bengtsson B, Hussein M. Reduction of intraocular pressure and glaucoma 
progression: results from the Early Manifest Glaucoma Trial. Arch Ophthalmol. 2002;120:1268-79.

60. Vasudevan SK, Gupta V, Crowston JG. Neuroprotection in glaucoma. Indian J Ophthalmol. 2011;59:S102.

61. Hillman $\mathrm{CH}$, Erickson KI, Kramer AF. Be smart, exercise your heart: exercise effects on brain and cognition. Nat Rev Neurosci. 2008;9:58.

62. Mattson MP. Energy intake and exercise as determinants of brain health and vulnerability to injury and disease. Cell Metab. 2012;16:706-22.

63. Chrysostomou V, Kezic JM, Trounce IA, Crowston JG. Forced exercise protects the aged optic nerve against intraocular pressure injury. Neurobiol Aging. 2014;35:1722-5.

64. Tielsch JM, Katz J, Sommer A, Quigley HA, Javitt JC. Hypertension, perfusion pressure, and primary open-angle glaucoma: a population-based assessment. Arch Ophthalmol. 1995;113:216-21.

65. Yip JL, Broadway DC, Luben R, Garway-Heath DF, Hayat S, Dalzell N, et al. Physical activity and ocular perfusion pressure: the EPIC-Norfolk eye study. Invest Ophthalmol Vis Sci. 2011;52:8186-92.

66. Vaynman S, Ying Z, Gomez-Pinilla F. Hippocampal BDNF mediates the efficacy of exercise on synaptic plasticity and cognition. Eur J Neurosci. 2004;20:2580-90.

67. Rasmussen P, Brassard P, Adser H, Pedersen MV, Leick L, Hart $\mathrm{E}$, et al. Evidence for a release of brain-derived neurotrophic factor from the brain during exercise. Exp Physiol. 2009;94:1062-9.

68. Martin KR, Quigley HA, Zack DJ, Levkovitch-Verbin H, Kielczewski J, Valenta D, et al. Gene therapy with brain-derived neurotrophic factor as a protection: retinal ganglion cells in a rat glaucoma model. Invest Ophthalmol Vis Sci. 2003;44:4357-65.

69. Ghaffariyeh A, Honarpisheh N, Heidari MH, Puyan S, Abasov F. Brain-derived neurotrophic factor as a biomarker in primary openangle glaucoma. Optom Vis Sci. 2011;88:80-5.

70. Munemasa Y, Kitaoka Y. Molecular mechanisms of retinal ganglion cell degeneration in glaucoma and future prospects for cell body and axonal protection. Front Cell Neurosci. 2013;6:60.

71. Chrysostomou V, Galic S, Wijngaarden P, Trounce IA, Steinberg GR, Crowston JG. Exercise reverses age-related vulnerability of the retina to injury by preventing complement-mediated synapse elimination via a BDNF-dependent pathway. Aging Cell. 2016;15:1082-91.

72. Vieira GM, Oliveira HB, de Andrade DT, Bottaro M, Ritch R. Intraocular pressure variation during weight lifting. Arch Ophthalmol. 2006;124:1251-4.

73. He Z, Bui BV, Vingrys AJ. The rate of functional recovery from acute IOP elevation. Invest Ophthalmol Vis Sci. 2006;47:4872-80.

74. Risner D, Ehrlich R, Kheradiya NS, Siesky B, McCranor L, Harris A. Effects of exercise on intraocular pressure and ocular blood flow: a review. J Glaucoma. 2009;18:429-36.

75. Loprinzi PD, Swenor BK, Ramulu PY. Age-related macular degeneration is associated with less physical activity among US adults: cross-sectional study. PLoS ONE. 2015;10:e0125394.

76. Coleman HR, Chan CC, Ferris FL III, Chew EY. Age-related macular degeneration. Lancet. 2008;372:1835-45.
77. Knudtson MD, Klein R, Klein BE. Physical activity and the 15year cumulative incidence of age-related macular degeneration: the Beaver Dam Eye Study. Br J Ophthalmol. 2006;90:1461-3.

78. Beatty S, Koh HH, Phil M, Henson D, Boulton M. The role of oxidative stress in the pathogenesis of age-related macular degeneration. Surv Ophthalmol. 2000;45:115-34.

79. Munch IC, Linneberg A, Larsen M. Precursors of age-related macular degeneration: associations with physical activity, obesity, and serum lipids in the inter99 eye study. Invest Ophthalmol Vis Sci. 2013;54:3932-40.

80. Yousif Subhi AS, Falk MK, Sørensen TL. In patients with neovascular age-related macular degeneration, physical activity may influence C-reactive protein levels. Clin Ophthalmol. 2014;8:15.

81. Subhi Y, Sørensen TL. Physical activity patterns in patients with early and late age-related macular degeneration. Dan Med J. 2016;63:A5303.

82. McGuinness MB, Karahalios A, Simpson JA, Guymer RH, Robman LD, Hodge AM. et al. Past physical activity and agerelated macular degeneration: the Melbourne Collaborative Cohort Study. Br J Ophthalmol. 2016;100:1353-8.

83. Seddon JM, Cote J, Davis N, Rosner B. Progression of age-related macular degeneration: association with body mass index, waist circumference, and waist-hip ratio. Arch Ophthalmol. 2003;121:785-92.

84. Rovner BW, Casten RJ. Activity loss and depression in agerelated macular degeneration. Am J Geriatr Psychiatry. 2002;10:305-10.

85. Ding J, Wong TY. Current epidemiology of diabetic retinopathy and diabetic macular edema. Curr Diab Rep. 2012;12:346-54.

86. Sigal RJ, Kenny GP, Wasserman DH, Castaneda-Sceppa C. Physical activity/exercise and type 2 diabetes. Diabetes Care. 2004;27:2518-39.

87. Ding J, Ikram MK, Cheung CY, Wong TY. Retinal vascular calibre as a predictor of incidence and progression of diabetic retinopathy. Clin Exp Optom. 2012;95:290-6.

88. Anuradha S, Dunstan DW, Healy GN, Shaw JE, Zimmet PZ, Wong TY, et al. Physical activity, television viewing time, and retinal vascular caliber. Med Sci Sports Exerc. 2011;43:280-6.

89. Tikellis G, Anuradha S, Klein R, Wong TY. Association between physical activity and retinal microvascular signs: the Atherosclerosis Risk in Communities (ARIC) Study. Microcirculation. 2010;17:381-93.

90. Di Francescomarino S, Sciartilli A, Di Valerio V, Di Baldassarre A, Gallina S. The effect of physical exercise on endothelial function. Sports Med. 2009;39:797-812.

91. Loprinzi PD, Joyner C. Accelerometer-determined physical activity and mortality in a national prospective cohort study: considerations by visual acuity. Prev Med. 2016;87:18-21.

92. Tang J, Kern TS. Inflammation in diabetic retinopathy. Prog Retin Eye Res. 2011;30:343-58.

93. American Diabetes Association. Physical activity/exercise and diabetes. Diabetes Care. 2004;27:s58-62.

94. Kasapis C, Thompson PD. The effects of physical activity on serum C-reactive protein and inflammatory markers: a systematic review. J Am Coll Cardiol. 2005;45:1563-9. 